\title{
The supramolecularly complexes of calix[4]arene derivatives toward favipiravir antiviral drug (used to treatment of COVID-19): a DFT study on the geometry optimization, electronic structure and infrared spectroscopy of adsorption and sensing
}

\author{
Numan Yuksel ${ }^{1} \cdot$ Ahmet Köse $^{1} \cdot$ M. Ferdi Fellah ${ }^{1}$ (i) \\ Received: 10 December 2020 / Accepted: 29 May 2021 / Published online: 5 June 2021 \\ (c) The Author(s), under exclusive licence to Springer Nature B.V. 2021
}

\begin{abstract}
While the world is in search of a vaccine that can cure COVID-19 disease, favipiravir is the most commonly used antiviral drug in the treatment of patients during the pandemic process. In this study, we investigated the host-guest interaction between the popular supramolecule calix[4]arene derivatives and the favipiravir drug by using the DFT (Density Functional Theory) method. The B3LYP hybrid method and 6-31G (d,p) basis set were utilized to determine the optimized structures of the host and guest molecules and their complexes. The negative adsorption energy $(\Delta \mathrm{E})$ and adsorption enthalpy $(\Delta \mathrm{H})$ calculated for the complexes formed between calix[4]arene compounds and favipiravir drug molecule mentioned that adsorption of favipiravir molecule was an exothermic process on calix[4]arene structures. On the other hand, among the calixarene derivatives in the study, Gibbs free energy change $(\Delta \mathrm{G})$ value for the adsorption was only negative on calix[4]arene4 molecule. The infrared spectroscopy (IR) calculations were performed by examining the $\mathrm{C}=\mathrm{O}, \mathrm{O}-\mathrm{H}$ and $\mathrm{NH}_{2}$ vibrational frequencies to see the adsorption behavior in the favipiravir-calix[4]arene complex. After adsorption of the favipiravir molecule, HOMO-LUMO gap values decreased significantly for the structures and therefore electrical conductivity increased proportionally. In addition, sensor response factors, Fermi energy levels and workfunction changes of calix[4]arene derivatives were calculated and examined. Charge transfer between the four calix[4]arene compounds and the favipiravir molecule has occurred after adsorption. This attributes that calix[4]arene derivatives can be used as a well-suited favipiravir sensor (electronic and workfunction) and adsorbent at room temperature. Based on the calculations made to see the solvent effect on the adsorption of favipiravir it was determined that it did not affect the interaction between the drug molecule and the calix[4]arene compound too much and the adsorption energy turned into a slightly less negative value.
\end{abstract}

Keywords DFT $\cdot$ Calix[4]arene $\cdot$ Favipiravir $\cdot$ Detection $\cdot$ Adsorption

\section{Introduction}

COVID-19 outbreaks spread rapidly all over the world. There are no vaccines and specific drugs that can be used to treat this virus so far (November 2020). Antiviral drugs such as chloroquine, hydroxychloroquine, lopinavir/ritonavir, favipiravir and remdesivir have been used for the treatment [1-3]. Among these antiviral drugs, favipiravir used for the treatment of influenza is noteworthy. Successful results have

M. Ferdi Fellah

mferdi.fellah@btu.edu.tr

1 Department of Chemical Engineering, Bursa Technical University, Mimar Sinan Campus, 16310 Bursa, Turkey been obtained with the use of favipiravir, which acts as an RNA-dependent RNA inhibitor, against coronavirus [4-8]. Favipiravir drug can cause side effects such as diarrhea, a decrease in neutrophil count and an increase in uric acid level in the blood [5, 9]. By the widespread use of favipiravir in COVID-19 pandemic, adsorption and detection of favipiravir molecule have become more important.

The therapeutic efficacy of drug molecules in vivo depends on reaching the target area without losing their properties. During the drug molecules reach the targeted area, they can interact with biochemical substances, therefore become deactivated and lose their effectiveness [10]. Interaction during this transport may cause some problems in the delivery, absorption and excretion of drugs to the cells. 
Excellent drug carriers are needed in the pharmaceutical industry to overcome these problems $[11,12]$. Drug carriers increase the biodistribution by reducing the drug dosage to be used and overcome the diffusion problem between cells [13]. Macrocyclic amphiphiles exhibited some advantages in drug delivery. While these substances increase drug solubility and stability, they can also decrease drug dosage $[14,15]$.

Calix $[n]$ arenes $(n=$ number of phenolic units), one of these macrocyclic molecules, has gained attention in recent years with its use in drug delivery and drug sensor systems $[13,16]$. Calix [n]arene derivatives provide some advantages with the properties gained by their functionalization with groups such as $\mathrm{R}-\mathrm{SO}_{3} \mathrm{H}$, tert-butyl, iso-propyl, - $\mathrm{COOH}$ and $-\mathrm{OH}$. In addition to the functional diversity of the upper and lower rims in calixarenes, their chemical stability, hydrophobic cavity, zero toxicity and controlled release profiles make calixarenes suitable for drug adsorbents and sensors $[13,17]$. Moreover, these molecules have been used as drug carriers in cancer treatment. It sensitizes the tumor microenvironments and provides controlled release. In addition to these, it provides the opportunity to protect the drugs from side reactions that cause deactivation $[18,19]$. Drug carrying and controlled release are associated with the adsorption of the drug on the carrier molecule. In order to understand the thermodynamic and structural properties between host and guest complex in drug adsorption, computational studies have been carried out along with experimental studies. Significant studies have been conducted to investigate these computational vehicle systems and to find new carrier materials [20-26]. Chen et al. achieved high encapsulation efficiency in the use of calix[4]arene as a carrier for paclitaxel, a cancer drug, and observed that these paclitaxel-loaded calixarenes improved the uptake of the drug into cells [27]. Athar et al. examined the host-guest relationship of calix[4]arene with lapatinib and nilotinib drugs by the semi-experimental PM3 method, and found that nilotinib $(-217.9 \mathrm{~kJ} / \mathrm{mol})$ and lapatinib $(-246.9 \mathrm{~kJ} / \mathrm{mol})$ have high binding energies onto calix[4]arene compound [28]. In a similar study reported previously, the adsorption energy value of 5-fluorouracil (5-FU) onto calix[4] arene was computed to be $-98 \mathrm{~kJ} / \mathrm{mol}$ by DFT method and it was found that calix[4]arenes have appropriate adsorption properties for 5-FU at room temperature [29].

Besides the adsorption of drugs, the sensor studies of drugs draw attention. It is important to be able to monitor and determine the effects of drugs on both humans and the environment. By its recognition ability of calixarene compounds, it has achieved successful results in the detection and separation of drugs in wastewater [30, 31]. Calixarenes are good sensors for some drugs as well as providing excellent selectivity, sensitivity and stability for long-term use [32-35]. Due to their derivatizability and appropriate molecular size, calix[4]arene compounds are expected to form a good complex with the favipiravir molecule. In this study, adsorption and sensor properties of favipiravir molecule onto calix[4]arene derivatives were investigated by DFT method.

\section{Computational method}

In this study, all of the quantum chemical calculations are based upon the DFT method [36]. The DFT calculations have been utilized in the Gaussian09 software [37, 38]. Using the B3LYP hybrid formalism method, which also consists of the exchange and correlation impacts, geometry optimization and energy calculations were carried out $[39,40]$. B3LYP hybrid method has been stated to be one of the DFT methods for the high-quality theoretical calculation procedure for organic chemistry [41]. The basis set $6-31 \mathrm{G}(\mathrm{d}, \mathrm{p})$ was used in calculations for all atoms. Four calix[4]arene compounds that could interact with the favipiravir molecule have been used in this research. These four compounds are derived from each other. The first of these compounds is the $p$-tert-butyl calix[4]arene compound which is called as calix[4]arene1 (the basic calix[4]arene compound) and the calix[4]arene2 molecule is obtained by removing of tert-butyl groups of calix[4] arene 1 compound $[42,43]$. The calix[4]arene 3 and the calix[4]arene 4 compounds are the structures formed by derivatizing calix[4]arene 2 compound, and the IUPAC namings are 25,27-bis(3-mercaptopropoxy)-26,28-dihydroxy calix[4]arene and 5,17-Bis[N-(4-carboxypiperidino) methyl]-25,27-bis(3-mercaptopropoxy)-26,28-dihydroxy calix[4]arene, respectively [32]. Schematic representations of calix[4]arene compounds examined in this study are shown in Fig. 1 (drawn on the Perkinelmer-ChemOffice website).

DFT calculations were used to optimize the geometries (to obtain the equilibrium geometry (EG)) and obtain energy values for adsorption. In this analysis, zero-point energy (ZPE) corrections are included in the energy values. In this study, basis-set superposition error (BSSE) correction using the counterpoise method was not taken into account due to its very small effects [44]. Its effect on the B3LYP hybrid method was determined in the range of approximately $1-2.5 \mathrm{~kJ} / \mathrm{mol}$ [45]. In addition, these values are likely to be similar for each of these systems and hence would not affect the results based on relative energies. In addition, vibrational frequency, thermal energy and thermal enthalpy values were calculated at room temperature and atmospheric pressure. The organic host calix[4]arene compounds and the favipiravir molecule were firstly optimized structurally by DFT calculations. The following energy values were calculated by subsequent equations in Gaussian software. 


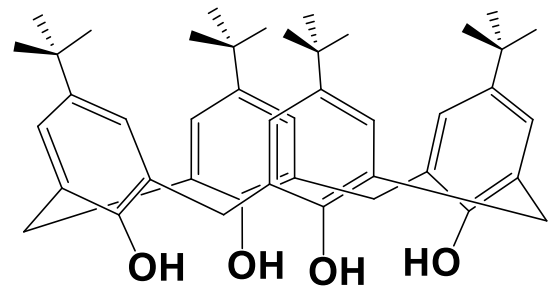

Calix[4]arene1

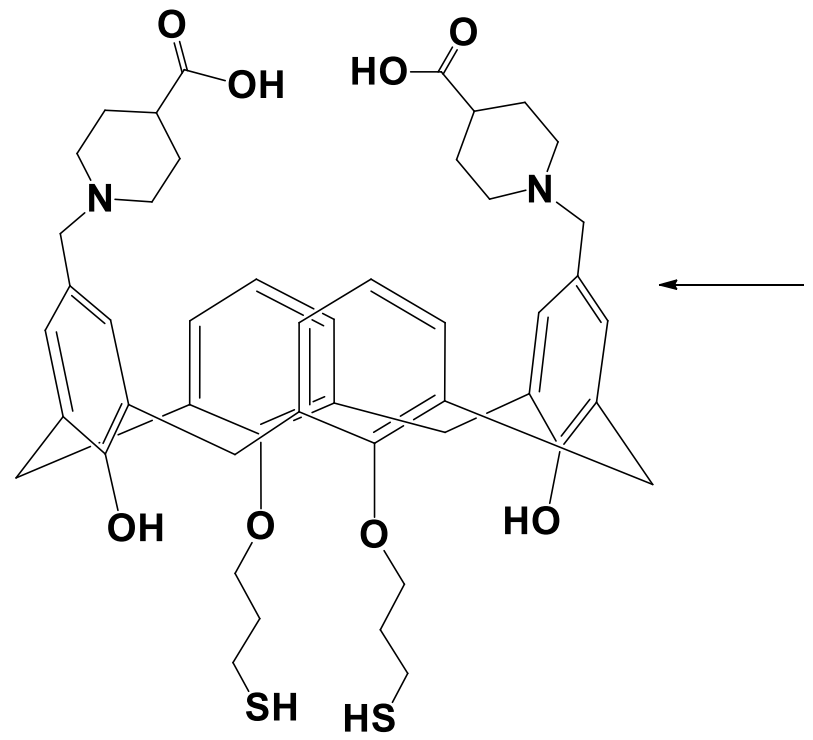

Calix[4]arene4

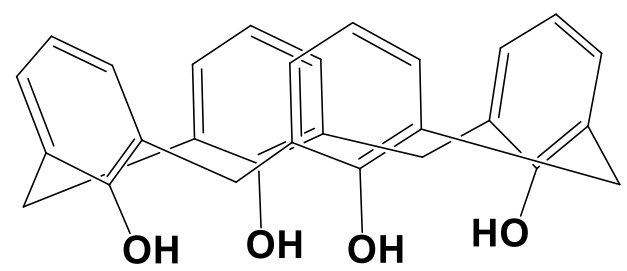

Calix[4]arene2

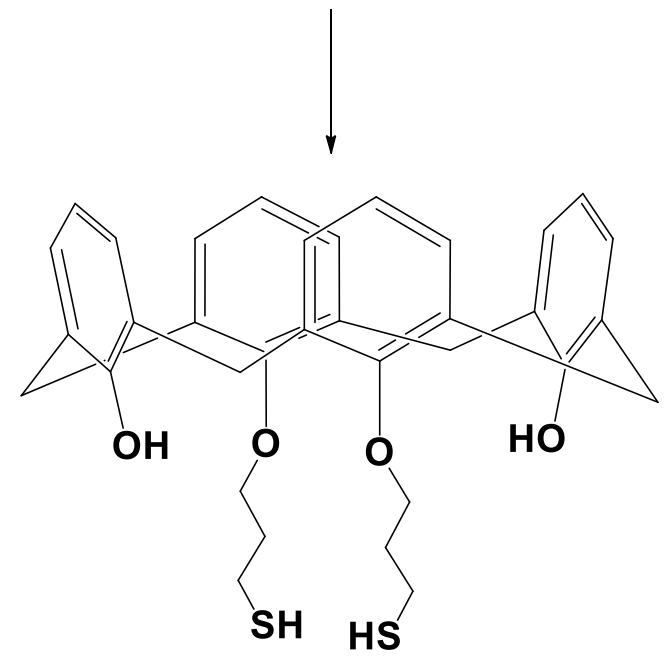

Calix[4]arene3

Fig. 1 Schematic representation for calix[4]arene compounds utilized in this study for the adsorption of favipiravir molecule

$E=E_{\text {electronic }}+Z P E+E_{\text {vibrational }}+E_{\text {rotational }}+E_{\text {translational }}$

$H=E+R T$

$G=H-T S$

$\mathrm{E}$ is the sum of the electronic, ZPE and thermal energies, $\mathrm{H}$ is the sum of the thermal energies and enthalpy, $\mathrm{G}$ is sum of thermal enthalpy and free energy, $\mathrm{T}$ is the temperature used for the vibrational frequency calculations, $S$ is the entropy and $\mathrm{R}$ is the global ideal gas constant. Below equation (Eq. 4) was used to calculate the relative adsorption energy, adsorption enthalpy and Gibbs free energy values. In this equation, the calix[4] arene compounds are called as the host and favipiravir molecule is called as the guest. The structure formed by host and guest molecules after adsorption is called as the complex. The inclusion processes of the host and guest molecules were handled in 1:1 ratio. In adsorption calculation, the structures were prepared by placing the guest molecule horizontally on the upper rim region of the host molecule. Thus, every atom in the favipiravir molecule was provided to interact with the calixarene compound at the same distance, and different favipiravir configurations were not required to be calculated. In addition, the adsorption of the favipiravir molecule to the outer side of the functional group of the calix[4]arene4 compound has been calculated.

$\Delta(\mathrm{E} / \mathrm{H} / \mathrm{G})=(E / H / G)_{\text {Complex }}-\left[(E / H / G)_{\text {Guest }}+(E / H / G)_{\text {Host }}\right]$

Moreover, the HOMO (highest occupied molecular orbital) and the LUMO (lowest unoccupied molecular orbital) energy values were computed by full analysis of population. Full population analysis refers to a full Mulliken population analysis that controls the printing of molecular orbitals and several types of population analysis [46]. Chemical hardness, chemical potential, electronegativity, electrophilicity, HOMO-LUMO energy gap and HOMO and LUMO energies ( $\varepsilon_{\text {HOMO }}$ and $\varepsilon_{\text {LUMO }}$, 
respectively) were calculated by using below the equations based on Koopmans approach [47, 48].

Chemical hardness $(\eta)=\frac{I-A}{2}$

Chemical potential $(\mu)=-\frac{I+A}{2}$

Electronegativity $(\chi)=-\mu$

Electrophilicity $(\omega)=\frac{\mu^{2}}{2 \eta}$

HOMO - LUMO energy gap $E_{g}=\varepsilon_{\text {LUMO }}-\varepsilon_{\text {HOMO }}$

where $\mathrm{I} \approx-\epsilon_{\text {HOMO }}$ and $\mathrm{A} \approx-\epsilon_{L U M O}$.

The criteria of the convergence utilized in DFT calculations: 0.0012 rad is for gradients of root-mean-square (rms) displacement, $0.0018 \mathrm{bohr}$ is for max displacement, 0.0003 hartreee/radian is for rms force and 0.00045 hartree/bohr is for max force. Furthermore, the parameters for convergence SCF used in DFT calculations; for RMS change in the density matrix and maximum change in density matrix are 0.00000001 and 0.000001 , respectively. We applied GaussSum software [49] to draw the density of states (DOS) schemes. NBO atomic charges of atoms were obtained by Natural Bond Orbital (NBO) population analysis [50]. In order to reproduce experimental fundamentals, all vibrational IR frequency values have been scaled by the value of 0.9613 [51].

\section{Results and discussion}

The host and guest molecules were firstly optimized geometrically by DFT calculations. The EG of guest molecule (favipiravir) was determined by taking the total charge as zero and SM (Spin Multiplicity) as a singlet. The optimized geometries of calix[4]arene compounds and favipiravir molecule have been shown in Fig. 2 and the optimized geometries for the complexes of the favipiravir antiviral drug with calix[4]arene compounds are given in Fig. 3. Here, the complexes formed between calix[4] arene1, calix[4]arene2, calix[4]arene3 and calix[4]arene4 compounds and the favipiravir molecule are named complex1, complex2, complex 3 and complex4, respectively. In order to see the accuracy of B3LYP hybrid method and 6-31G(d, p) basis set used in DFT calculations, calix[4] arene 1 compound was compared with experimental data. In a study previously reported in the literature [52], the length of $\mathrm{C}_{\mathrm{Ar}}-\mathrm{C}$ bond length and $\mathrm{C}_{\mathrm{Ar}}-\mathrm{C}-\mathrm{C}_{\mathrm{Ar}}$ bond angle $\left(\mathrm{C}_{\mathrm{Ar}}=\right.$ the phenol's ortho position carbon $)$ in methylene bridges of calix[4]arene 1 compound were given as $1.51 \AA$ and $113.9^{\circ}$, respectively. And in this study, these values were calculated as $1.52 \AA, 113.7^{\circ}$, respectively. The energy values for favipiravir adsorption onto calix [4] arene structures were listed in Table 1. When the adsorption energy values and adsorption enthalpy values for the complex formation of favipiravir and calix[4]arene compounds were examined, negative values were obtained for all complexes. This result attributes that the adsorptions of the favipiravir molecule on the complexes are an exothermic process. The adsorption energy $(\Delta \mathrm{E})$ and enthalpy $(\Delta \mathrm{H})$ for complex 4 were calculated as $-40.6 \mathrm{~kJ} /$ $\mathrm{mol}$ and $-43.0 \mathrm{~kJ} / \mathrm{mol}$, respectively. The reason why the best adsorption values belong to complex 4 is the presence of $-\mathrm{OH}$ groups in the upper rim region of calix[4]arene4 compound. Because hydrogen bonds between - $\mathrm{OH}$ groups in calix[4]arene4 compound and $-\mathrm{OH}$ and $-\mathrm{NH}_{2}$ groups in favipiravir molecule strengthen adsorption. Due to their negative binding energies, it is possible that hydroxyl groups that can be found in both rims of calixarene compounds enter into intermolecular hydrogen interactions. Complex 4 is potentially more stable with hydrogen bond interactions [53-55]. Also, as can be seen from Fig. 3, the $-\mathrm{NH}_{2}$ and $-\mathrm{OH}$ groups of the favipiravir molecule together play an important role in the interactions in all complexes. These values (in Table 1) are significantly higher than the previous reported values. In the literature, adsorption enthalpy values for favipiravir adsorption on Si-doped and Fe-doped fullerenes have been calculated as $-182 \mathrm{~kJ} / \mathrm{mol}$ and $-149.6 \mathrm{~kJ} / \mathrm{mol}$, respectively [56, 57]. However, it is not desirable for the adsorption energy change values to be large, because that much energy must be given for desorption. Looking at the Gibbs free energy change $(\Delta G)$ values, it has been revealed that adsorption can occur spontaneously for only complex 4 , since the $\Delta \mathrm{G}$ value for the complex 4 is negative $(-2.0 \mathrm{~kJ} / \mathrm{mol})$. In addition, the point to be stated about this result; in this spontaneously forming complex 4 , the host-guest interaction between the functional group and the drug molecule is not in the hydrophobic cavity of the calix[4]arene4 compound, but from outside of the compound. Because in the optimized geometry of the calix [4]arene 4 compound, the $-\mathrm{OH}$ group of the functional group is located on the outside of the structure. In the adsorption study carried out in the hydrophobic cavity, the positive $\Delta \mathrm{G}$ value and the small $\Delta \mathrm{E}$ value support this result.

In order to investigate the sensitivity of the electronic properties of calix [4]arene compounds to favipiravir molecule, it has been used two parameters, such as $\mathrm{E}_{\mathrm{g}}$ and workfunction $(\Phi)$ to see the sensor properties of calix[4] arene structures for favipiravir molecule. Here $\mathrm{E}_{\mathrm{g}}$ is the gap between the HOMO and LUMO energies. Based on the literature, $\mathrm{E}_{\mathrm{g}}$ can be a good indicator for calculating the 


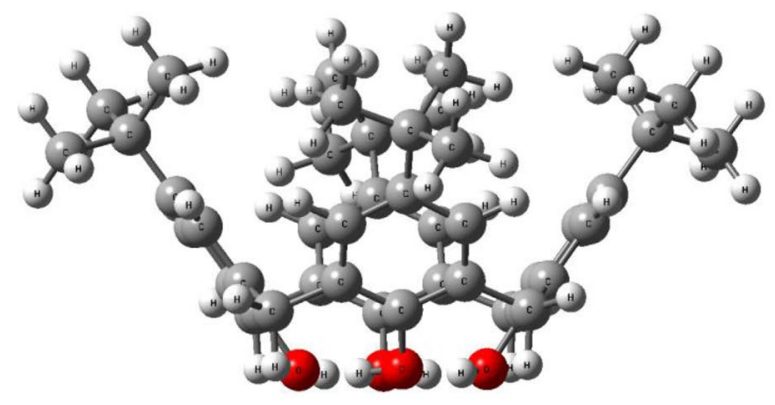

Calix[4]arene1

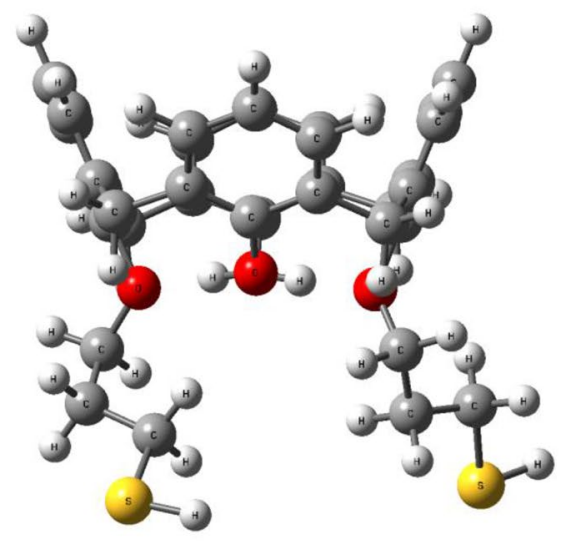

Calix[4]arene3

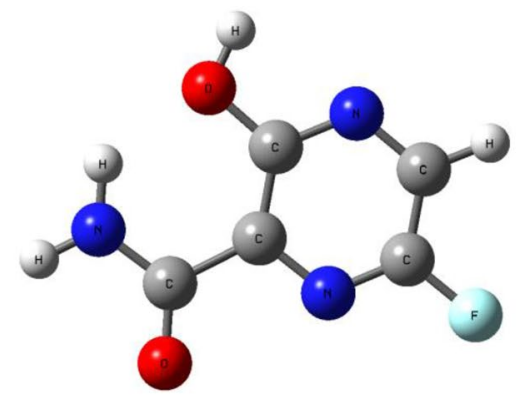

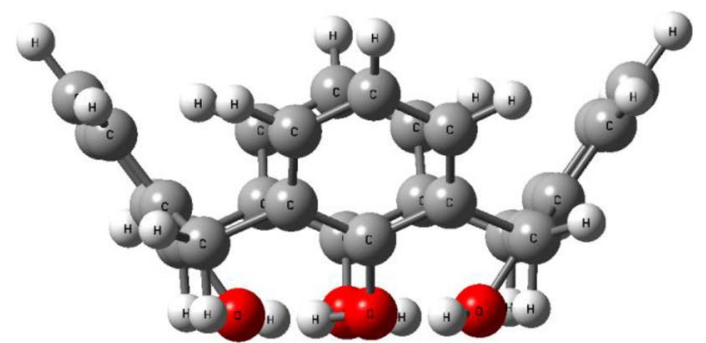

Calix[4]arene2

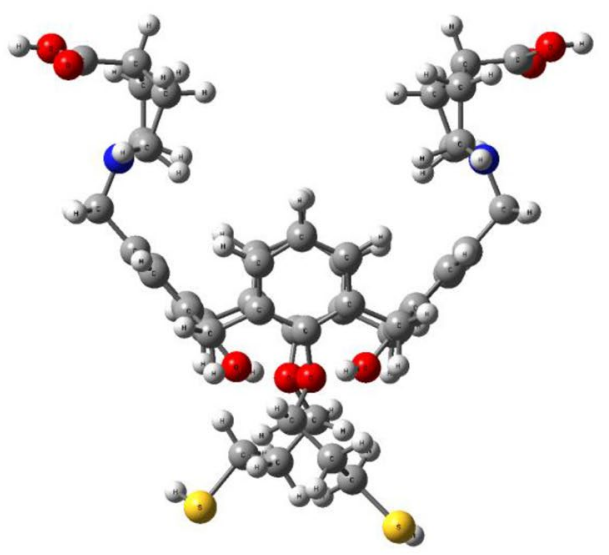

Calix[4]arene4

\section{Favipiravir}

Fig. 2 Optimized structures of the calix[4]arene derivatives (host molecules) and favipiravir (guest molecule)

sensitivity of nanosensors has been shown repeatedly [58, 59]. It has been also mentioned there is a following correlation between $\mathrm{E}_{\mathrm{g}}$ and electrical conductivity $(\sigma)[60,61]$ :

$\sigma=A T^{\frac{3}{2}} \exp \left(-\frac{E_{g}}{2 \kappa T}\right)$

where $\kappa$ is the Boltzmann's constant, A (electrons $/ \mathrm{m}^{3} \mathrm{~K}^{3 / 2}$ ) is a constant and $\mathrm{T}$ is temperature. Numerous papers have shown that the results of using this formula are confirmed by the results of experimental studies [62, 63]. Eq. (10) demonstrates that the decrease in $\mathrm{E}_{\mathrm{g}}$ increases the population of conduction electrons exponentially. Therefore, the presence of the chemical in the environment increases the electrical conductivity.

The sensor response factor $(\mathrm{R})$ is defined in following equation [64] to predict the magnitude of the electrical change:

$$
R=\frac{\sigma_{2}}{\sigma_{1}}=\exp \left[-\frac{\left(E_{g_{2}}-E_{g_{1}}\right)}{2 \kappa T}\right]=\exp \left(-\frac{\Delta E_{g}}{2 \kappa T}\right)
$$




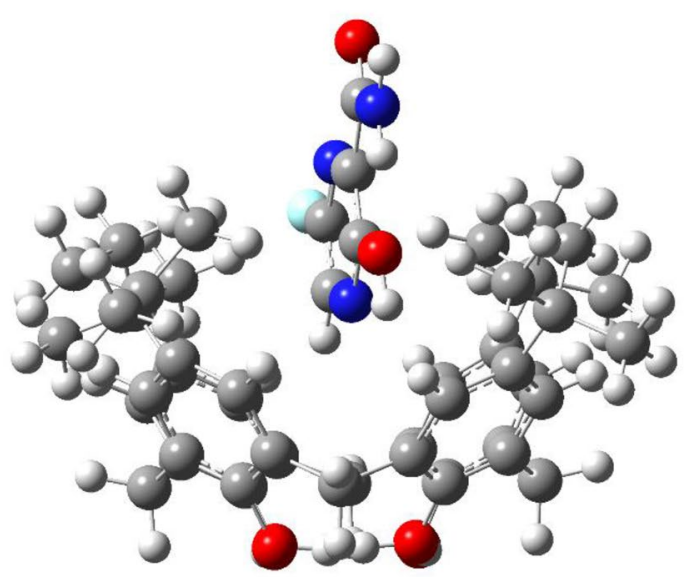

Complex 1

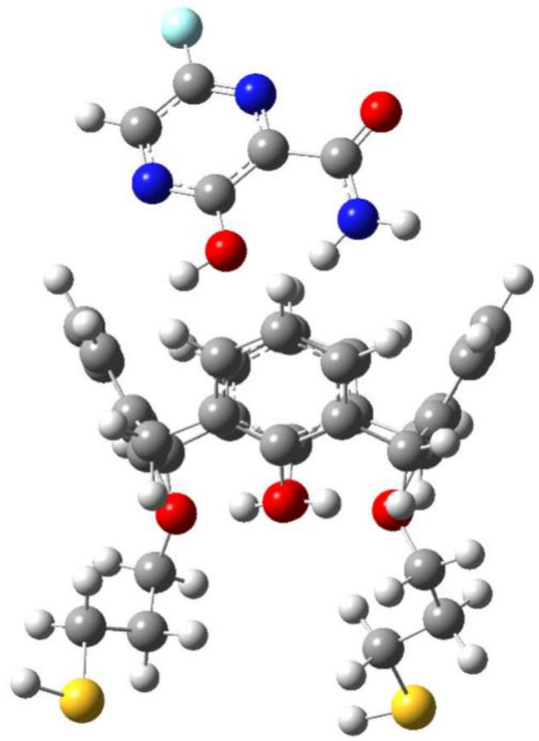

Complex 3

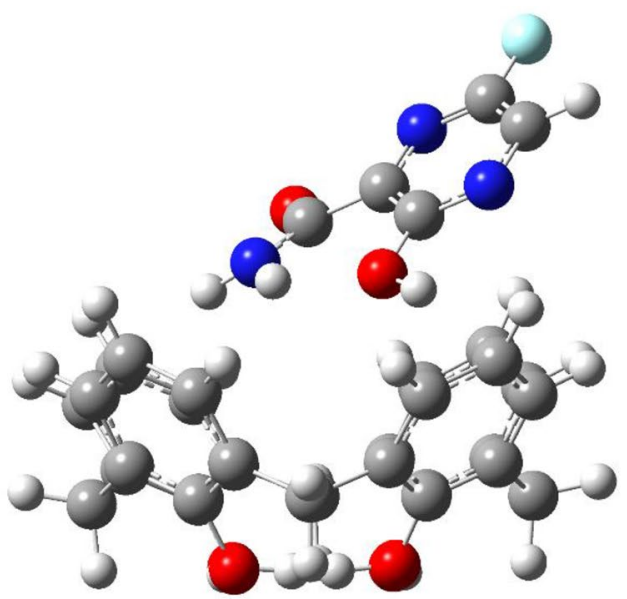

Complex 2

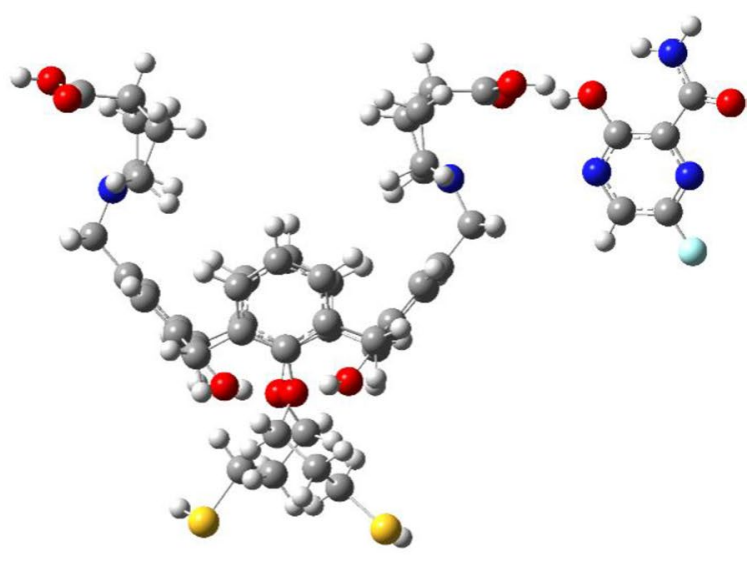

Complex 4

Fig. 3 Optimized geometries of the host-guest complex between the calix[4]arene derivatives and favipiravir molecule after adsorption

Table 1 Thermodynamic energy values for the adsorption of favipiravir molecule on calix[4]arene compounds (values are in units of $\mathrm{kJ} /$ $\mathrm{mol}$ )

\begin{tabular}{llll}
\hline Structure & $\Delta \mathrm{E}$ & $\Delta \mathrm{H}$ & $\Delta \mathrm{G}$ \\
\hline Calix[4]arene1 & -23.5 & -25.9 & 27.3 \\
Calix[4]arene2 & -23.0 & -25.5 & 20.4 \\
Calix[4]arene3 & -16.3 & -18.8 & 26.8 \\
Calix[4]arene4 & -40.6 & -43.0 & -2.0 \\
\hline
\end{tabular}

Here $\sigma 1$ and $\sigma 2$ are the electrical conductivity signals of the calix[4]arene molecule and calix[4]arene-favipiravir complex, respectively. In other words $\sigma 1$ and $\sigma 2$ are the electrical conductivity of the structures before and after adsorption, respectively.

R-values were calculated using Eq. (12). According to the results, it has been revealed that the complexes have a ratio between the response factor and $\Delta \mathrm{E}_{\mathrm{g}}$ values. The sensor response factor was quite high for all complexes. The complex4 has the highest $\mathrm{R}$ value and this value was calculated to the $1.2 \times 10^{11}$. Moreover, R-values for complex 1 , complex 2 and complex 3 were computed as $2 \times 10^{10}, 2.6 \times 10^{9}$ 
and $4.1 \times 10^{9}$, respectively. According to these results, it can be mentioned that the sensitivity of calix[4]arene compounds to the favipiravir drug was very high.

If the adsorption of a material changes the work function $(\Phi)$ value of the sensor, it affects the gate voltage, gives an electrical signal, and helping chemical recognition $[65,66]$. The $\Phi$ is assumed to be the amount of energy required to remove an electron from the Fermi level.

$\Phi=V_{e l}(+\infty)-E_{F}$

Here, $\mathrm{E}_{\mathrm{F}}$ is Fermi level energy and $\mathrm{V}_{\mathrm{el}}(+\infty)$ is the electrostatic potential energy of the electron, located far from the surface of the material and considered to be zero. Supposing $\mathrm{V}_{\mathrm{el}}(+\infty)=0$, $\Phi$ equals to $-\mathrm{E}_{\mathrm{F}}$. Then the Fermi level can be computed as follows:

$E_{F}=\varepsilon_{\text {HOMO }}+\frac{E_{g}}{2}=\frac{\varepsilon_{\text {HOMO }}+\varepsilon_{L U M O}}{2}$

Table 2 shows the electronic properties of calix[4]arene molecules, including HOMO, LUMO, $\mathrm{E}_{\mathrm{g}}$, Fermi level and workfunction $(\Phi)$ change well from favipiravir drug adsorption. Considering the these calculated values, it has been determined that there was a serious decrease in the $\mathrm{E}_{\mathrm{g}}$ values of the calix[4]arene compounds in the study. This means that calix[4]arene compounds can be good candidates for sensing the favipiravir molecule. It is also stated in the table that the workfunctions $(\Phi)$ of these sensor candidates have increased by about 20 percent.

Chemical-hardness $(\eta)$, chemical-potential $(\mu)$, electronegativity $(\chi)$ and electrophilicity $(\omega)$ values calculated according to HOMO and LUMO values are listed in Table 3. According to the results, host molecules have become more soft structures after adsorption. Electronegativity of all calix[4]arene molecules increased with significantly increasing their chemical potential and electophilicity. Moreover, Natural Bond Orbital analysis (NBO) was used in this study to obtain NBO charge distributions before and after favipiravir molecule adsorption onto calix[4]arene structutes. The total charge of favipiravir
Table 3 Chemical hardness, chemical potential, electronegativity and electrophilicity values for the optimized calix[4]arene compounds and the optimized complexes (values are in units of $\mathrm{kJ} / \mathrm{mol}$ )

\begin{tabular}{lllll}
\hline Structure & $\begin{array}{l}\text { Chemical } \\
\text { hardness }(\eta)\end{array}$ & $\begin{array}{l}\text { Chemical } \\
\text { potential }(\mu)\end{array}$ & $\begin{array}{l}\text { Electron- } \\
\text { egativity } \\
(\chi)\end{array}$ & $\begin{array}{l}\text { Electro- } \\
\text { philicity } \\
(\omega)\end{array}$ \\
\hline Calix[4]arene1 & 251.4 & -290.6 & 290.6 & 167.9 \\
Complex1 & 195.2 & -370.8 & 370.8 & 357.7 \\
Calix[4]arene2 & 258.6 & -305.1 & 305.1 & 179.9 \\
Complex2 & 204.5 & -380.0 & 380.0 & 353.0 \\
Calix[4]arene3 & 249.8 & -286.0 & 286.0 & 163.8 \\
Complex3 & 194.6 & -370.6 & 370.6 & 352.9 \\
Calix[4]arene4 & 238.6 & -288.2 & 288.2 & 174.1 \\
Complex4 & 174.9 & -359.7 & 359.7 & 369.8 \\
\hline
\end{tabular}

molecule after the adsorption was calculated as $-0.004 \mathrm{e}$, $-0.056 \mathrm{e},-0.048 \mathrm{e}$ and $-0.053 \mathrm{e}$ on complex 1 , complex 2 , complex 3 and complex4, respectively. According to these results, it has been mentioned that charge transfer has occurred from calix[4]arene compounds to the drug molecule (favipiravir) in all complexes. Figure 4 represents the HOMO and LUMO illustrations of calix[4]arene structures and favipiravir molecule adsorbed calix[4]arene structures (namely complexes). According to the HOMO and LUMO analysis (Fig. 4), generally HOMOs are located in the electron-donating part (calix[4]arenes) while LUMOs are located in the electronreceiving part (favipiravir).

It should be noted that the extremely strong interactions do not detect the molecules as they demonstrate the trouble in desorbing the adsorbate and this system is subject to longer recovery times. The traditional transition theory predicts a much longer recovery time if the adsorption energy increases significantly. The following equation can be used to explain this situation $[61,63]$.

$\tau=\left(v_{0}\right)^{-1} \exp \left(-\mathrm{E}_{\mathrm{ad}} / \mathrm{kT}\right)$
Table 2 HOMO and LUMO energies, Fermi level $\left(\mathrm{E}_{\mathrm{F}}\right)$, work function $(\phi)$ and $\mathrm{HOMO}-$ LUMO energy gap $\left(\mathrm{E}_{\mathrm{g}}\right)$ values $(\mathrm{kJ} / \mathrm{mol})$

\begin{tabular}{lllllllll}
\hline Structures & $\mathrm{E}_{\text {Hомо }}$ & $\mathrm{E}_{\mathrm{LUMO}}$ & $\mathrm{E}_{\mathrm{g}}$ & $\Delta \mathrm{E}_{\mathrm{g}}$ & $\% \Delta \mathrm{E}_{\mathrm{g}}$ & $\mathrm{E}_{\mathrm{F}}$ & $\phi$ & $\% \Delta \phi$ \\
\hline Calix[4]arene1 & -541.9 & -39.2 & 502.8 & -118.3 & -23.5 & -290.6 & 290.6 & 21.6 \\
Complex1 & -563.0 & -178.6 & 384.4 & & & -370.8 & 370.8 & \\
Calix[4]arene2 & -563.7 & -46.5 & 517.2 & -108.2 & -20.9 & -305.1 & 305.1 & 19.7 \\
Complex2 & -584.5 & -175.5 & 409.0 & & & -380.0 & 380.0 & \\
Calix[4]arene3 & -535.9 & -36.2 & 499.6 & -110.4 & -22.1 & -286.0 & 286.0 & 22.8 \\
Complex3 & -565.3 & -176.0 & 389.3 & & & -370.6 & 370.6 & \\
Calix[4]arene4 & -526.8 & -49.6 & 477.2 & -127.4 & -26.7 & -288.2 & 288.2 & 19.9 \\
Complex4 & -534.6 & -184.8 & 349.8 & & & -359.7 & 359.7 & \\
\hline
\end{tabular}

The $\Delta \mathrm{E}_{\mathrm{g}}$ indicates the change of $\mathrm{E}_{\mathrm{g}}$ after the adsorption process. The $\% \Delta \phi$ indicates the change of $\phi$ after the adsorption 
HOMO
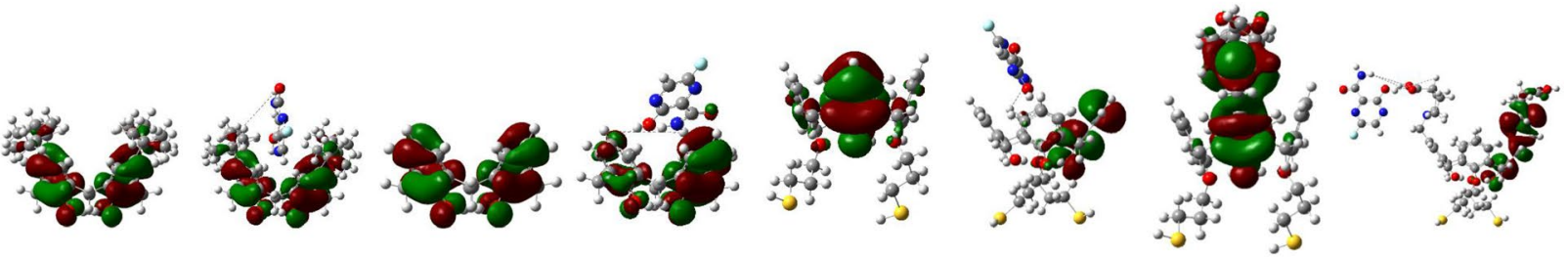

LUMO
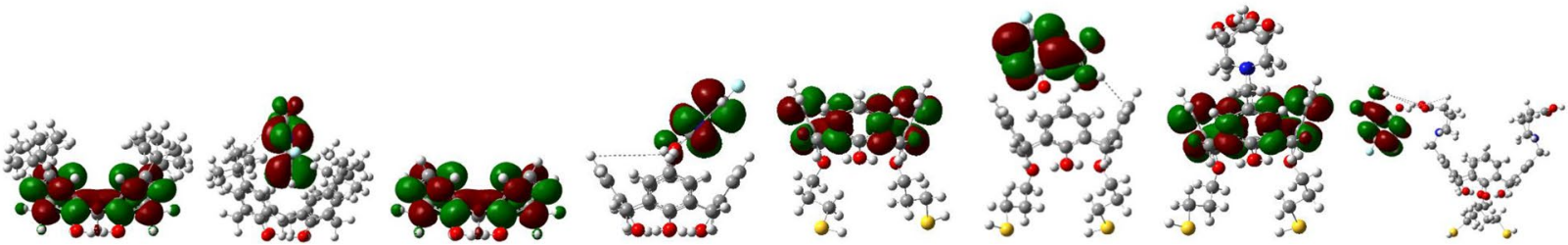

Fig. 4 HOMO and LUMO representations of the optimized structures

Here the recovery time is $\tau$, energy of adsorption is $E_{a d}$, temperature of adsorption is $\mathrm{T}, \mathrm{k}$ is the constant of Boltzmann $\left(\sim 8.368 \times 10^{-3} \mathrm{~kJ} / \mathrm{mol}\right)$ and the attempt frequency $\left(\nu_{0}\right)$ is commonly assumed to be a typical value $\sim 10^{12} \mathrm{~s}^{-1}$ $[67,68]$. This equation shows that recovery times increase exponentially with more negative adsorption energy $\left(\mathrm{E}_{\mathrm{ad}}\right)$ values. The favipiravir molecule's adsorption energy is not too high to prevent the recovery of the calix[4] arene1, calix[4]arene2, calix[4]arene3 and calix[4]arene4

Calix[4]arene1

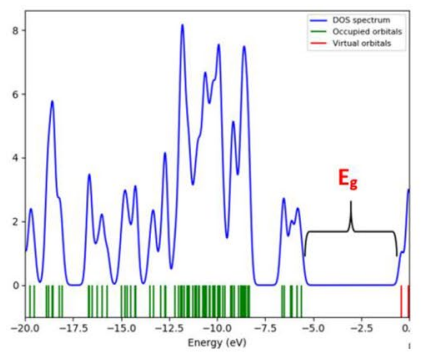

Complex1
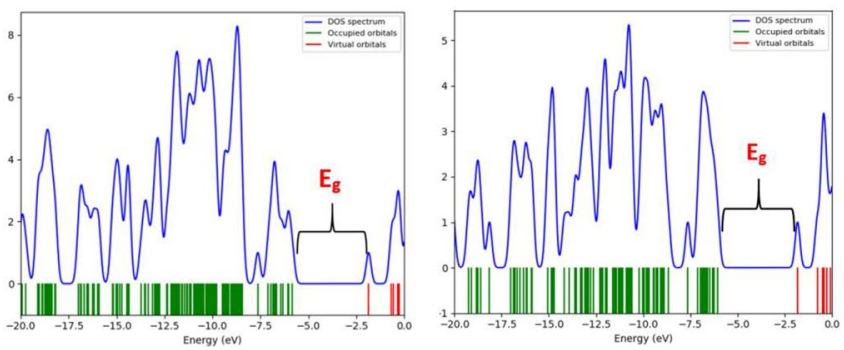

depending on the equation stated. The recovery times were calculated in the range of $1.14 \times 10^{-5} \mathrm{~s}-6.8 \times 10^{-10} \mathrm{~s}$.

The density of states (DOS) of the host structures and the host-guest complex structures were presented in Fig. 5. As shown in this figure, the distance between DOS plots were shifted by the reduction of the $\mathrm{E}_{\mathrm{g}}$ of calix[4]arene structures. This is in good agreement with the charge transfer between the guest molecule and the host molecules. The DOS analysis confirms the calix[4]arene structures band gap reduction, which means that the calix[4]arene molecules' electrical
Calix[4]arene3

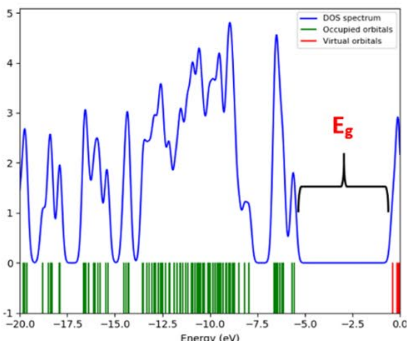

Complex3

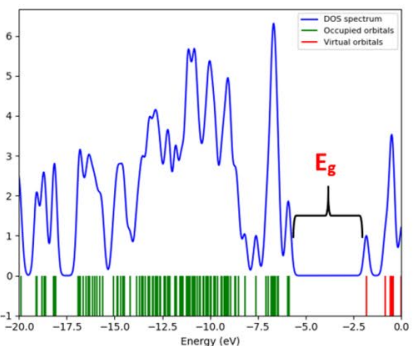

Calix[4]arene4

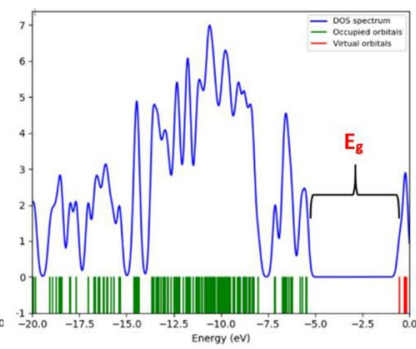

Complex 4

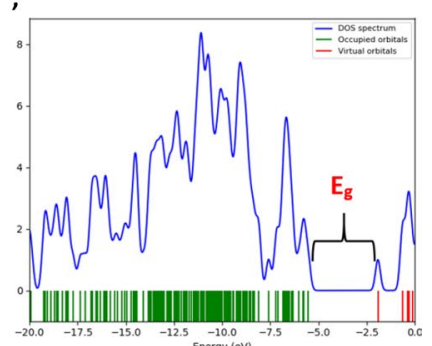

Fig. 5 Density of states (DOS) schemes for the optimized structures 
conductance has increased. Figure 6 gives the distribution of electrostatic potential (ESP) for calix[4]arene structures and favipiravir adsorbed calix[4]arene complexes. The positive and negative areas of the Van der Waals surface described blue and red colors, respectively, on the ESP maps [69, 70]. The electrostatic potential decreases by different colors in order to blue-green-yellow-red. According to the ESP distribution analysis, it is seen that the blue colors increase after the complex formation. This indicates that the electrostatic potential increases between host and guest molecules).

The vibrational frequency values of favipiravir molecule and complexes are given in the Table 4. The adsorption behavior of the favipiravir molecule on calix[4]arene compounds was investigated by taking into account the changes in the most important peaks in the infrared spectra of favipiravir. When the stretching frequencies of the favipiravir molecule and 4 complexes are examined, the frequencies of the $\mathrm{C}=\mathrm{O}, \mathrm{NH}_{2}$ and $\mathrm{O}-\mathrm{H}$ groups of favipiravir draw attention. The vibrational frequencies of the important functional groups of the favipiravir molecule calculated in the theoretical studies previously reported are approximately $v$ $\mathrm{C}=\mathrm{O}: 1700, \nu_{\text {symmetrical }} \mathrm{N}-\mathrm{H}: 3450, \nu_{\text {asymmetrical }} \mathrm{N}-\mathrm{H}: 3600$ [71] and $\nu \mathrm{C}-\mathrm{F}: 1320, \nu \mathrm{C}=\mathrm{O}: 1810, \nu_{\mathrm{s}} \mathrm{N}-\mathrm{H}: 3450, \nu \mathrm{N}-\mathrm{H}: 3650$ $\left(\mathrm{cm}^{-1}\right)$ [57]. These values are comparable with the calculated frequency values. In this study, IR frequency values were calculated for optimized calix[4]arene compounds and the characteristic vibration peaks obtained are: calix [4] arene1; v O-H:3204 $\left(\mathrm{cm}^{-1}\right)$, calix[4]arene2; $\nu$ O-H:3208 $\left(\mathrm{cm}^{-1}\right)$, calix[4]arene3; $v$ O-H:3413, 3452, $v$ S-H:2575 $\left(\mathrm{cm}^{-1}\right)$, calix[4]arene4; $\nu$ O-H:3408, 3447, $\nu$ S-H:2582, $v$ $\mathrm{C}=\mathrm{O}: 1756\left(\mathrm{~cm}^{-1}\right)$. These results are comparable with the IR frequency values experimentally reported as $\nu \mathrm{O}-\mathrm{H}: 3435$

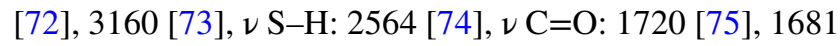
[76] $\left(\mathrm{cm}^{-1}\right)$. After adsorption, $\mathrm{O}-\mathrm{H}$ and $\mathrm{NH}_{2}$ frequencies of favipiravir were redshifted according to free favipiravir (See Fig. 7). Especially in complex4, the significant decrease in $\mathrm{O}-\mathrm{H}$ frequency explains the high adsorption energy. In addition, in $\mathrm{O}-\mathrm{H}$ frequency shifts of calix[4]arene1, calix[4] arene2, calix[4]arene 3 compounds and in $\mathrm{O}-\mathrm{H}$ and $\mathrm{C}=\mathrm{O}$ frequency shifts of calix[4]arene 4 compound support the high adsorption energy values in the complexes.

In this study, the adsorption processes were carried out in gas phase. In order to investigate the effect of solvent on the adsorption of favipiravir on calix[4]arenes, calculations have been made again. For this purpose the Polarizable Continuum Model (PCM) was utilized for the calculations. Therefore, the effect of solvent was investigated for complex 4 because it has the lowest adsorption energy in the gas phase. When water was used as solvent, there was little reduction in the adsorption of the favipiravir molecule on calix[4]arene 4 and the $\Delta \mathrm{E}_{\text {solvent }}$ (adsorption in solvent) becomes less negative $(-39.3 \mathrm{~kJ} / \mathrm{mol}) . \Delta \mathrm{E}_{\text {sol-gas }}$ is difference between $\Delta E$ s of complex 4 in the solvent and gas phase. The $\Delta \mathrm{E}_{\text {sol-gas }}$ for complex4 has been calculated from the following equation [77]:

\section{Calix[4]arene1}

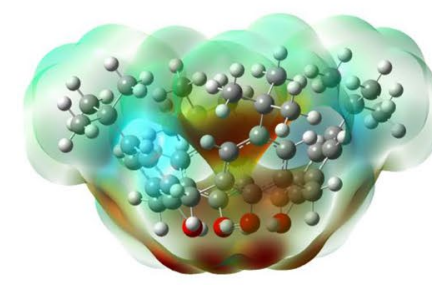

Complex1

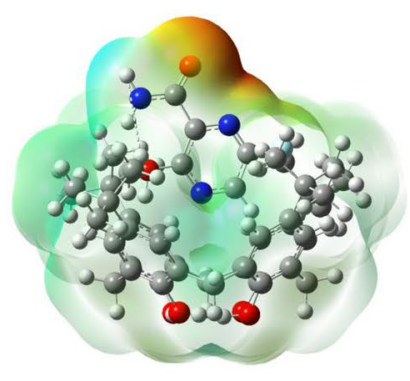

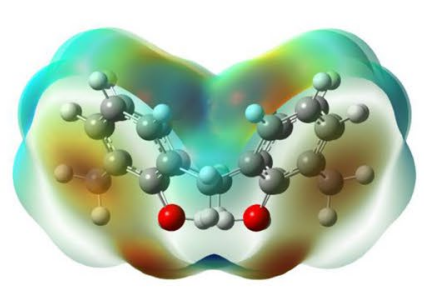

Calix[4]arene2

Complex2

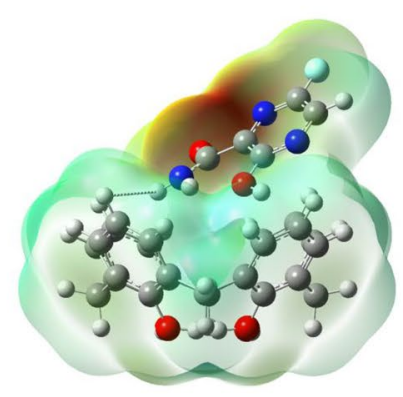

Calix[4]arene3

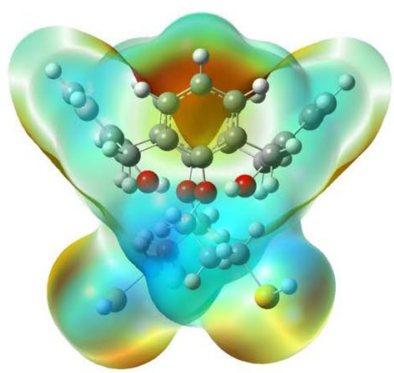

Complex3

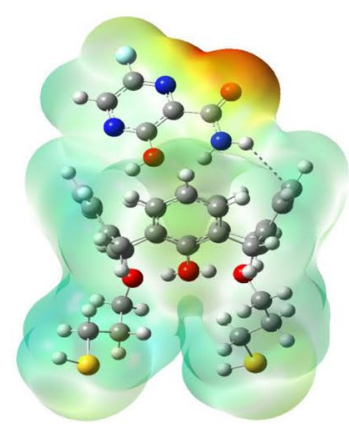

Calix[4]arene4

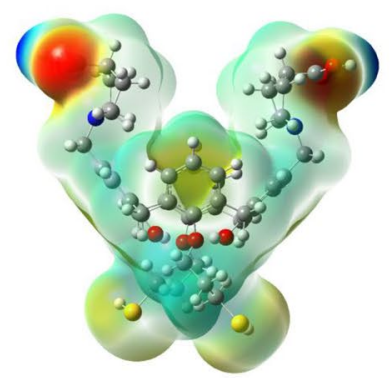

Complex4

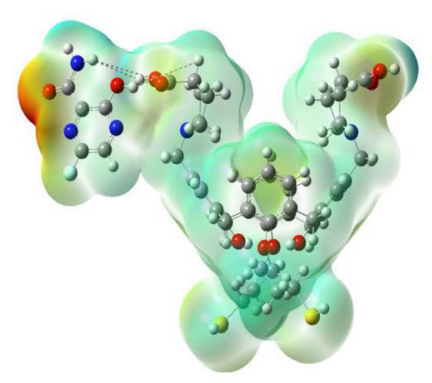

Fig. 6 Electrostatic potential (ESP) distribution maps with projection for the optimized structures 
Table 4 Vibrational frequency values of favipiravir molecule and complexes (values are in units of $\mathrm{cm}^{-1}$ )

\begin{tabular}{llllll}
\hline Vibrational mode & Favipiravir & Complex 1 & Complex 2 & Complex 3 & Complex 4 \\
\hline O-H rocking & 467 & 505 & 502 & 489 & 482 \\
N-H twisting & 608 & 613 & 622 & 617 & 620 \\
C-F stretching & 1302 & 1295 & 1305 & 1302 & 1299 \\
C-O stretching & 1439 & 1432 & 1444 & 1444 & 1440 \\
N-H scissoring & 1562 & 1564 & 1565 & 1564 & 1558 \\
C=O stretching & 1735 & 1731 & 1722 & 1728 & 1734 \\
C-H stretching & 3084 & 3108 & 3077 & 3076 & 3077 \\
N-H symmetric stretching & 3460 & 3458 & 3430 & 3460 & 3455 \\
O-H stretching & 3598 & 3598 & 3560 & 3501 & 3596 \\
N-H asymmetric stretching & 3618 & 3507 & 3508 & 3595 & 2997 \\
\hline
\end{tabular}

$\Delta E_{\text {sol-gas }}=\Delta E_{\text {solvent }}-\Delta E_{\text {gas phase }}$

where $\Delta \mathrm{E}_{\text {solvent }}$ and $\Delta \mathrm{E}_{\text {gas phase }}$ are the adsorption energies of complex 4 in the solvent and gas phase, respectively. The
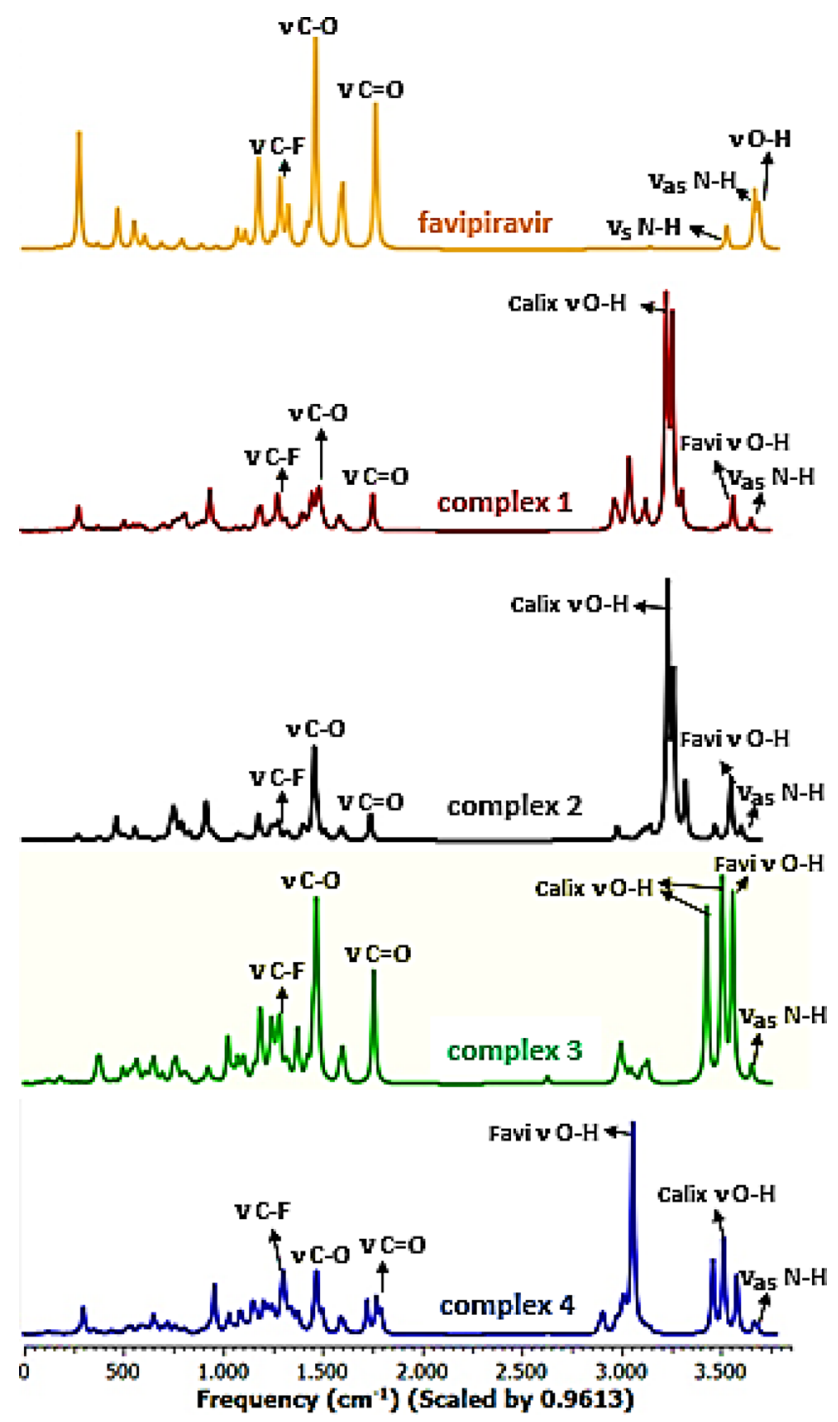

Fig. 7 Infrared spectrums of optimized favipiravir molecule and complex structures
$\Delta \mathrm{E}_{\text {sol-gas }}$ value has been computed as $1.3 \mathrm{~kJ} / \mathrm{mol}$. This result shows that the difference between adsorption in solvent and gas phase adsorption is very small. Additionally, the solvation energies $\left(\Delta \mathrm{E}_{\mathrm{sol}}\right)$ for calix[4]arene4, favipiravir and complex4 structure have been calculated from the following equation:

$\Delta E_{\text {sol }}=E_{\text {solution }}-E_{\text {gas }}$

where $\mathrm{E}_{\text {solution }}$ and $\mathrm{E}_{\text {gas }}$ are the total energies of each system in solvent and gas phase, respectively. The $\Delta \mathrm{E}_{\mathrm{sol}}$ values have been computed as $-83.1,-42.6$ and $-124.4 \mathrm{~kJ} /$ mol for calix[4]arene4, favipiravir and complex4, respectively. This means that the $\mathrm{E}_{\text {solution }}$ of the complex 4 is more negative when compared to the total $\mathrm{E}_{\text {solution }}$ of favipiravir molecule and calix[4]arene4. Additionally, the calculated electronic dipole moment of favipiravir molecule in solvent was calculated as 7.46 Debye. These results designate that the favipiravir molecule has been slightly soluble in water. This result is consistent with a previously published study in literature [78]. Consequently, use of water as a solvent has little affected the adsorption of favipiravir on calix[4]arene4. Additionally, one can mention that inclusion of favipiravir in calix[4]arene cavity may involves partial dehydration of the cavity upon entrance of a perhaps already hydrated favipiravir.

The theoretical results of this study show that calixarene compounds that can be derivatized with different functional groups can adsorb and detect favipiravir and similar drug molecules. In particular, using a wide variety of derivatives of these hosts could help studies in this area, where it can improve the adsorption and detection of drug molecules.

\section{Conclusions}

It is important to investigate nanomaterials that can be both the carrier and the detector of the favipiravir drug, which is widely used in the treatment processes against the recently emerging COVID-19 disease. In this study, the adsorption 
and sensor properties of calix[4]arene compounds toward favipiravir antiviral drug were investigated using the DFT method. It has been resulted in that the calix[4]arene compounds are good adsorbents against the favipiravir molecule. In addition, Gibbs free energy change for the adsorption of favipiravir molecule on calix[4]arene 4 structure was only determined as negative value. Thus, it has been seen that the derivatizability of calixarene structures leads to better results. Also, the IR study supports the high adsorption energy values of favipiravir on calixarene. Another focus is the alteration of electrical conductivity in host-guest complex formations. It has been seen that reducing the energy gaps of HOMO-LUMO of all calix[4]arenes increase their electrical conductivity, so all calix[4]arene compounds can be utilized as nanosensor for favipiravir detection. Besides, it was determined that charge transfer took place between calix[4]arene compounds and favipiravir molecule in all complexes. Furthermore, the calculations with solvent identified that the drug molecule weakly interacts with the calix[4]arene compound and the adsorption energy becomes slightly less negative value. Considering these results, the calixarene derivatives give good results in sensing or adsorption of favipiravir drug at room temperature. As a conclusion, calix[4]arene structures used in this study might be utilized as both electronic sensor and workfunction sensor for favipiravir molecule detection.

Acknowledgements The numerical-calculations reported in this paper were partially performed at TUBITAK-ULAKBIM, High-Performance and Grid-Computing-Center-(TRUBA resources).

\section{Declarations}

Conflicts of interest The authors declare that they have no conflict interests.

\section{References}

1. Yanai, H.: Favipiravir: a possible pharmaceutical treatment for COVID-19. J. Endocrinol. Metab. 10(2), 33-34 (2020). https:// doi.org/10.14740/jem645

2. Hagar, M., Ahmed, H.A., Aljohani, G., Alhaddad, O.A.: Investigation of some antiviral N-heterocycles as COVID 19 drug: Molecular Docking and DFT calculations. Int. J. Mol. Sci. 21(11), 3922 (2020). https://doi.org/10.3390/ijms21113922

3. McKee, D.L., Sternberg, A., Stange, U., Laufer, S., Naujokat, C.: Candidate drugs against SARS-CoV-2 and COVID-19. Pharmacol. Res. 157, 104859 (2020). https://doi.org/10.1016/j.phrs.2020. 104859

4. Shiraki, K., Daikoku, T.: Favipiravir, an anti-influenza drug against life-threatening RNA virus infections. Pharmacol. Ther. 209, 107512 (2020). https://doi.org/10.1016/j.pharmthera.2020. 107512
5. Du, Y.X., Chen, X.P.: Favipiravir: pharmacokinetics and concerns about clinical trials for 2019-nCoV infection. Clin. Pharmacol. Ther. (2020). https://doi.org/10.1002/cpt.1844

6. Khambholja, K., Asudani, D.: Potential repurposing of Favipiravir in COVID-19 outbreak based on current evidence. Travel Med. Infect. Dis. 35, 101710 (2020). https://doi.org/10.1016/j.tmaid. 2020.101710

7. Costanzo, M., De. Giglio, M.A.R., Roviello, G.N.: SARS-CoV-2: recent reports on antiviral therapies based on lopinavir/ritonavir, darunavir/umifenovir, hydroxychloroquine, remdesivir, favipiravir and other drugs for the treatment of the new coronavirus. Curr. Med. Chem. (2020). https://doi.org/10.2174/092986732766620 0416131117

8. Tu, Y.-F., Chien, C.-S., Yarmishyn, A.A., Lin, Y.-Y., Luo, Y.-H., Lin, Y.-T., Lai, W.-Y., Yang, D.-M., Chou, S.-J., Yang, Y.-P.: A review of SARS-CoV-2 and the ongoing clinical trials. Int. J. Mol. Sci. 21(7), 2657 (2020). https://doi.org/10.3390/ijms21072657

9. Mishima, E., Anzai, N., Miyazaki, M., Abe, T.: Uric acid elevation by favipiravir, an antiviral drug. Tohoku J. Exp. Med. 251(2), 87-90 (2020). https://doi.org/10.1620/tjem.251.87

10. Jana, S., Suryavanshi, K.K., Maiti, S., Jana, S.: Calixarenes containing supramolecular vehicles for drug delivery. In: Polysaccharide Carriers for Drug Delivery, pp. 477-495. Elsevier, Amsterdam. (2019). https://doi.org/10.1016/B978-0-08-1025536.00017-9

11. Yahyavi, M., Badalkhani-Khamseh, F., Hadipour, N.L.: Adsorption behavior of pristine, Al-, and Si-doped carbon nanotubes upon 5-fluorouracil. Chem. Phys. Lett. 750, 137492 (2020). https://doi.org/10.1016/j.cplett.2020.137492

12. Lee, S.-C., Arya, V., Yang, X., Volpe, D.A., Zhang, L.: Evaluation of transporters in drug development: current status and contemporary issues. Adv. Drug Deliv. Rev. 116, 100-118 (2017). https:// doi.org/10.1016/j.addr.2017.07.020

13. Galindo-Murillo, R., Olmedo-Romero, A., Cruz-Flores, E., Petrar, P., Kunsagi-Mate, S., Barroso-Flores, J.: Calix [n] arene-based drug carriers: a DFT study of their electronic interactions with a chemotherapeutic agent used against leukemia. Comput. Theor. Chem. 1035, 84-91 (2014). https://doi.org/10.1016/j.comptc. 2014.03.001

14. Fontana, R.M., Milano, N., Barbara, L., Di. Vincenzo, A., Gallo, G., Meo, P.L.: Cyclodextrin-calixarene nanosponges as potential platforms for $\mathrm{pH}$-dependent delivery of tetracycline. Chem. Select 4(33), 9743-9747 (2019). https://doi.org/10.1002/slct.201902373

15. Zheng, Z., Geng, W.C., Xu, Z., Guo, D.S.: Macrocyclic amphiphiles for drug delivery. Isr. J. Chem. 59(10), 913-927 (2019). https:// doi.org/10.1002/ijch.201900032

16. Kumar, R., Sharma, A., Singh, H., Suating, P., Kim, H.S., Sunwoo, K., Shim, I., Gibb, B.C., Kim, J.S.: Revisiting fluorescent calixarenes: From molecular sensors to smart materials. Chem. Rev. 119(16), 9657-9721 (2019). https://doi.org/10.1021/acs. chemrev.8b00605

17. Athar, M., Ranjan, P., Jha, P.C.: A DFT study of inclusion complexes of substituted calix [n] arenes with dasatinib and lapatinib. J. Mol. Graph. Model. 84, 160-165 (2018). https://doi.org/10. 1016/j.jmgm.2018.06.018

18. Fahmy, S.A., Ponte, F., Abd El-Rahman, M.K., Russo, N., Sicilia, E., Shoeib, T.: Investigation of the host-guest complexation between 4-sulfocalix [4] arene and nedaplatin for potential use in drug delivery. Spectrochim. Acta A. 193, 528-536 (2018). https:// doi.org/10.1016/j.saa.2017.12.070

19. Hu, X.-Y., Gao, J., Chen, F.-Y., Guo, D.-S.: A host-guest drug delivery nanosystem for supramolecular chemotherapy. J. Control. Release (2020). https://doi.org/10.1016/j.jconrel.2020.05.008

20. Veclani, D., Tolazzi, M., Melchior, A.: Molecular interpretation of pharmaceuticals' adsorption on carbon nanomaterials: theory 
meets experiments. Processes 8(6), 642 (2020). https://doi.org/10. 3390/pr8060642

21. Tariq, A., Nazir, S., Arshad, A.W., Nawaz, F., Ayub, K., Iqbal, J.: DFT study of the therapeutic potential of phosphorene as a new drug-delivery system to treat cancer. RSC Adv. 9(42), 2432524332 (2019). https://doi.org/10.1039/C9RA02778E

22. Bagheri, R., Babazadeh, M., Vessally, E., Eshaghi, M., Bekhradnia, A.: Si-doped phagraphene as a drug carrier for adrucil anticancer drug: DFT studies. Inorg. Chem. Commun. 90, 8-14 (2018). https://doi.org/10.1016/j.inoche.2018.01.020

23. Zhu, H., Zhao, C., Cai, Q., Fu, X., Sheykhahmad, F.R.: Adsorption behavior of 5-aminosalicylic acid drug on the B12N12, AlB11N12 and GaB11N12 nanoclusters: A comparative DFT study. Inorg. Chem. Commun. 114, 107808 (2020). https://doi. org/10.1016/j.inoche.2020.107808

24. Abdolahi, N., Singla, P., Soltani, A., Javan, M., Aghaei, M., Heidari, F., Sedighi, S.: Gold decorated B12N12 nanocluster as an effective sulfasalazine drug carrier: a theoretical investigation. Phys. E. 124, 114296 (2020). https://doi.org/10.1016/j.physe. 2020.114296

25. Shahabi, M., Raissi, H.: Investigation of the solvent effect, molecular structure, electronic properties and adsorption mechanism of Tegafur anticancer drug on Graphene nanosheet surface as drug delivery system by molecular dynamics simulation and density functional approach. J. Incl. Phenom. Macrocycl. Chem. 88(3-4), 159-169 (2017). https://doi.org/10.1007/s10847-017-0713-9

26. Mahdavifar, Z., Moridzadeh, R.: Theoretical prediction of encapsulation and adsorption of platinum-anticancer drugs into single walled boron nitride and carbon nanotubes. J. Incl. Phenom. Macrocycl. Chem. 79(3-4), 443-457 (2013). https://doi.org/10.1007/ s10847-013-0367-1

27. Chen, M.X., Li, T., Peng, S., Tao, D.: Supramolecular nanocapsules from the self-assembly of amphiphilic calixarene as a carrier for paclitaxel. New J. Chem. 40, 9923-9929 (2016). https://doi. org/10.1039/c6nj01986b

28. Athar, M., Lone, M.Y., Jha, P.C.: Designing of calixarene based drug carrier for dasatinib, lapatinib and nilotinib using multilevel molecular docking and dynamics simulations. J. Incl. Phenom. Macrocycl. Chem. 90, 157-169 (2017). https://doi.org/10.1007/ s10847-017-0773-x

29. Yuksel, N., Fellah, M.F.: Host-guest complex properties of calix[4]arene derivatives: a DFT study of adsorption and sensing of an anticancer drug, 5-fluorouracil. Chem. Monthly 152, 217-228 (2021). https://doi.org/10.1007/s00706-021-02736-4

30. Zheng, Z., Yu, H., Geng, W.-C., Hu, X.-Y., Wang, Y.-Y., Li, Z., Wang, Y., Guo, D.-S.: Guanidinocalix [5] arene for sensitive fluorescence detection and magnetic removal of perfluorinated pollutants. Nat. Commun. 10(1), 1-9 (2019). https://doi.org/10.1038/ s41467-019-13775-1

31. de Namor, A.F.D., Al Nuaim, M., Salas, J.A.V., Bryant, S., Howlin, B.: A calix [4] arene derivative and its selective interaction with drugs (clofibric acid, diclofenac and aspirin). Eur. J. Pharm. Sci. 100, 1-8 (2017). https://doi.org/10.1016/j.ejps.2016.12.027

32. Kurzątkowska, K., Sayin, S., Yilmaz, M., Radecka, H., Radecki, J.: Calix [4] arene derivatives as dopamine hosts in electrochemical sensors. Sens. Actuators B. 218, 111-121 (2015). https://doi. org/10.1016/j.snb.2015.04.110

33. Alrabiah, H., Aljohar, H.I., Bakheit, A.H., Homoda, A.M., Mostafa, G.A.-H.: Comparative study of $\beta$-cyclodextrin, $\gamma$-cyclodextrin and 4-tert-butylcalix [8] arene ionophores as electroactive materials for the construction of new sensors for trazodone based on host-guest recognition. Drug Des. Dev. Ther. 13, 2283 (2019). https://doi.org/10.2147/DDDT.S201907

34. Liu, N., Fan, Y., Ma, Z., Lin, H., Xu, J.: Materials design and sensing mechanism of novel calix [6] arene composite for sensitively detecting amine drugs. Chin. Chem. Lett. (2020). https://doi.org/10.1016/j.cclet.2020.01.034

35. Temel, F.: Real-time and selective recognition of erythromycin by self-assembly of calix [4] arene on QCM sensor. J. Mol. Liq. 297, 111818 (2020). https://doi.org/10.1016/j.molliq.2019. 111818

36. Baerends, E.: Perspective on "Self-consistent equations including exchange and correlation effects". In: Theoretical Chemistry Accounts. vol. 103, pp. 265-269. Springer, New York (2000). https://doi.org/10.1007/s002140050031

37. Frisch, M., Trucks, G., Schlegel, H., Scuseria, G., Robb, M., Cheeseman, J., Scalmani, G., Barone, V., Mennucci, B., Petersson, G.: Official Gaussian 09 literature citation. www.gaussian. com/gtech/gur/mcitation.htm (2014).

38. Foresman, J., Frish, E.: Exploring chemistry. Gaussian Inc., Pittsburg (1996)

39. Becke, A.D.: Density-functional exchange-energy approximation with correct asymptotic behavior. Phys. Rev. A 38(6), 3098-3100 (1988). https://doi.org/10.1103/physreva.38.3098

40. Lee, C., Yang, W., Parr, R.G.: Development of the Colle-Salvetti correlation-energy formula into a functional of the electron density. Phys. Rev. B. 37(2), 785-789 (1988). https://doi.org/10.1103/ physrevb.37.785

41. Yuksel, N., Kose, A., Fellah, M.F.: A density functional theory study of molecular hydrogen adsorption on $\mathrm{Mg}$ site in OFF type zeolite cluster. Int. J. Hydrogen Energy (2020). https://doi.org/10. 1016/j.ijhydene.2020.02.110

42. Akpinar, M., Temel, F., Tabakci, B., Ozcelik, E., Tabakci, M.: A phenyl glycinol appended calix[4]arene film for chiral detection of ascorbic acid on gold surface. Anal. Biochem. 583, 113373 (2019). https://doi.org/10.1016/j.ab.2019.113373

43. Furer, V.L., Borisoglebskaya, E.I., Zverev, V.V., Kovalenko, V.I.: The hydrogen bonding and conformations of p-tert-butylcalix[4] arene as studied by IR spectroscopy and by DFT calculations. Spectrochim. Acta A. 62(1-3), 483-493 (2005). https://doi.org/ 10.1016/j.saa.2005.02.001

44. Fellah, M.F., Onal, I.: A DFT study on the [VO] 1+-ZSM-5 cluster: direct methanol oxidation to formaldehyde by $\mathrm{N} 2 \mathrm{O}$. Phys. Chem. Chem. Phys. 15, 13969-13977 (2013). https://doi.org/10. 1039/c3cp51637g

45. Kobko, N., Dannenberg, J.: Effect of basis set superposition error (BSSE) upon ab initio calculations of organic transition states. J. Phys. Chem. A 105, 1944-1950 (2001). https://doi.org/10.1021/ jp001970b

46. Cioslowski, J.: A new population analysis based on atomic polar tensors. J. Am. Chem. Soc. 111, 8333-8336 (1989). https://doi. org/10.1021/ja00204a001

47. Pearson, R.G.: Chemical hardness and density functional theory. J. Chem. Sci. 117, 369-377 (2005). https://doi.org/10.1007/BF027 08340

48. Pearson, R.G.: The electronic chemical potential and chemical hardness. J. Mol. Struct. 255, 261-270 (1992). https://doi.org/10. 1016/0166-1280(92)85014-C

49. O’Boyle, N.M., Tenderholt, A.L., Langner, K.M.: cclib: a library for package-independent computational chemistry algorithms. J. Comput. Chem. 29(5), 839-845 (2008). https://doi.org/10.1002/ jcc. 20823

50. Glendening, E. D., Reed, A. E., Carpenter, J. E. Weinhold, F.: NBO Version 3.1,.

51. Scott, A.P., Radom, L.: Harmonic vibrational frequencies: an evaluation of Hartree-Fock, Møller-Plesset, quadratic configuration interaction, density functional theory, and semiempirical scale factors. J. Phys. Chem. 100, 16502-16513 (1996). https:// doi.org/10.1016/0009-2614(96)00483-6

52. Sone, T., Ohba, Y., Moriya, K., Kumada, H., Ito, K.: Synthesis and properties of sulfur-bridged analogs of p-tert-Butylcalix[4] 
arene. Tetrahedron 53, 10689-10698 (1997). https://doi.org/10. 1016/S0040-4020(97)00700-X

53. Guendouzi, O., Guendouzi, A., Ouici, H.B., Brahim, H., Boumediene, M., Elkeurti, M.: A quantum chemical study of encapsulation and stabilization of gallic acid in $\beta$-cyclodextrin as a drug delivery system. Can. J. Chem. 98, 204-214 (2020). https://doi. org/10.1139/cjc-2019-0464

54. Imane, D., Leila, N., Fatiha, M., Abdelkrim, G., Mouna, C., Ismahan, L., Abdelazize, B., Brahim, H.: Investigation of intermolecular interactions in inclusion complexes of pyroquilon with cucurbit [n] urils $(\mathrm{n}=7,8)$ using DFT-D3 correction dispersion. J. Mol. Liq. 309, 113233 (2020). https://doi.org/10.1016/j.molliq.2020. 113233

55. Guendouzi, A., Mekelleche, S.M., Brahim, H., Litim, K.: Quantitative conformational stability host-guest complex of Carvacrol and Thymol with $\beta$-cyclodextrin: a theoretical investigation. J. Incl. Phenom. Macrocycl. Chem. 89, 143-155 (2017). https://doi. org/10.1007/s10847-017-0740-6

56. Parlak, C., Alver, Ö., Şenyel, M.: Computational study on favipiravir adsorption onto undoped-and silicon-decorated C60 fullerenes. J. Theor. Comput. Chem. 16(02), 1750011 (2017). https://doi.org/ 10.1142/S0219633617500110

57. Rad, A.S., Ardjmand, M., Esfahani, M.R., Khodashenas, B.: DFT calculations towards the geometry optimization, electronic structure, infrared spectroscopy and UV-vis analyses of Favipiravir adsorption on the first-row transition metals doped fullerenes; a new strategy for COVID-19 therapy. Spectrochim. Acta A 247, 119082 (2020). https://doi.org/10.1016/j.saa.2020.119082

58. Fellah, M.F.: Pt doped $(8,0)$ single wall carbon nanotube as hydrogen sensor: a density functional theory study. Int. J. Hydrogen Energy 44(49), 27010-27021 (2019). https://doi.org/10.1016/j. ijhydene.2019.08.169

59. Demir, S., Fellah, M.F.: A DFT study on Pt doped $(4,0)$ SWCNT: CO adsorption and sensing. Appl. Surf. Sci. 504, 14414 (2020). https://doi.org/10.1016/j.apsusc.2019.144141

60. Ahmadi, A., Hadipour, N.L., Kamfiroozi, M., Bagheri, Z.: Theoretical study of aluminum nitride nanotubes for chemical sensing of formaldehyde. Sens. Actuators B. 161(1), 1025-1029 (2012). https://doi.org/10.1016/j.snb.2011.12.001

61. Hadipour, N.L., Ahmadi Peyghan, A., Soleymanabadi, H.: Theoretical study on the Al-doped $\mathrm{ZnO}$ nanoclusters for $\mathrm{CO}$ chemical sensors. J. Phys. Chem. C 119(11), 6398-6404 (2015). https://doi. org/10.1021/jp513019z

62. Ahmadi Peyghan, A., Hadipour, N.L., Bagheri, Z.: Effects of Al doping and double-antisite defect on the adsorption of $\mathrm{HCN}$ on a BC2N nanotube: density functional theory Studies. J. Phys. Chem. C 117(5), 2427-2432 (2013). https://doi.org/10.1021/jp312503h

63. Eslami, M., Vahabi, V., Ahmadi Peyghan, A.: Sensing properties of $\mathrm{BN}$ nanotube toward carcinogenic 4-chloroaniline: a computational study. Phys. E. 76, 6-11 (2016). https://doi.org/10.1016/j. physe.2015.09.043

64. Li, L., Zhao, J.: Defected boron nitride nanosheet as an electronic sensor for 4-aminophenol: a density functional theory study. J. Mol. Liq. 306, 112696 (2020). https://doi.org/10.1016/j.molliq. 2020.112926

65. Korotcenkov, G.: Sensing layers in work-function-type gas sensors. In: Handbook of Gas Sensor Materials. Integrated Analytical Systems, pp. 377-388. (2013). https://doi.org/10.1007/978-14614-7165-3_17

66. Li, M., Wei, Y., Zhang, G., Wang, F., Li, M., Soleymanabadi, H.: A DFT study on the detection of isoniazid drug by pristine, $\mathrm{Si}$ and
Al doped C70 fullerenes. Phys. E. 118, 113878 (2020). https://doi. org/10.1016/j.physe.2019.113878

67. Koettgen, J., Zacherle, T., Grieshammer, S., Martin, M.: Ab initio calculation of the of oxygen diffusion in pure and samarium doped ceria. Phys. Chem. Chem. Phys. 19, 9957-9973 (2017). https:// doi.org/10.1039/c6cp04802a

68. Li, Y., Lin, N.: Combined scanning tunneling microscopy and kinetic Monte Carlo study on kinetics of $\mathrm{Cu}$-coordinated pyridylporphyrin supramolecular self-assembly on a $\mathrm{Au}(111)$ surface. Phys. Rev. B 84, 12 (2011). https://doi.org/10.1103/PhysRevB. 84.125418

69. Sjoberg, P.P.: Use of the electrostatic potential at the molecular surface to interpret and predict nucleophilic processes. J. Phys. Chem. C 94, 3959-3961 (1990). https://doi.org/10.1021/j1003 $73 \mathrm{a} 017$

70. Yu, G., Lyu, L., Zhang, F., Yan, D., Cao, W., Hu, C.: Theoretical and experimental evidence for rGO-4-PP Nc as a metal-free Fenton-like catalyst by tuning the electron distribution. RSC Adv. 8(6), 3312-3320 (2018). https://doi.org/10.1039/c7ra12573a

71. Rhyman, L., Tursun, M., Abdallah, H.H., Choong, Y.S., Parlak, C., Kharkar, P., Ramasami, P.: Theoretical investigation of the derivatives of favipiravir (T-705) as potential drugs for Ebola virus. Phys. Sci. Rev. 3(9), 3312 (2018). https://doi.org/10.1039/ c7ra12573a

72. Huang, H., Zhao, C., Ji, Y., Nie, R., Zhou, P., Zhang, H.: Preparation, characterization and application of p-tert-butyl-calix[4] arene-SBA-15 mesoporous silica molecular sieves. J. Hazard Mater. 178, 680-685 (2010). https://doi.org/10.1016/j.jhazmat. 2010.01.140

73. Eddaif, L., Shaban, A., Telegdi, J.: Sensitive detection of heavy metals ions based on the calixarene derivatives-modified piezoelectric resonators: A review. Int. J. Environ. Anal. Chem. 99, 824-853 (2019). https://doi.org/10.1080/03067319.2019.16167 08

74. Jlassi, K., Eid, K., Sliem, M.H., Abdullah, A.M., Chehimi, M.M.: Calix[4]arene-clicked clay through thiol-yne addition for the molecular recognition and removal of $\mathrm{Cd}(\mathrm{II})$ from wastewater. Sep. Purif. Technol. 251, 117853 (2020). https://doi.org/10.1016/j. seppur.2020.117383

75. Blond, P., Bevernaegie, R., Troian-Gautie, L., Lagrost, C., Hubert, J., Reniers, F., Raussens, V., Jabin, I.: Ready-to-use germanium surfaces for the development of FTIR-based biosensors for proteins. Langmuir 36, 12068-12076 (2020). https://doi.org/10.1021/ acs.langmuir.0c02681

76. Sayin, S., Yildiz, H.B., Eymur, S.: Synthesis of various calix[4] arene derivatives with mercaptoalkyl chains and their application in removing $\mathrm{Cr}(\mathrm{VI})$ from aqueous solution. Polycycl. Aromat. Compd. 38, 120-130 (2016). https://doi.org/10.1080/10406638. 2016.1169193

77. Rahmani, Z., Edjlali, L., Vessally, E., Hosseinian, A., Delir Kheirollahi Nezhad, P.: A DFT study on the sulfanilamide interaction with graphyne-like boron nitride nanosheet. J. Sulfur Chem. 41(5), 483-497 (2020). https://doi.org/10.1080/17415993.2020. 1754417

78. Evaluation and Licensing Division, Pharmaceutical and Food Safety Bureau Ministry of Health, Labour and Welfare Report, Report on the deliberation results. https://www.pmda.go.jp/files/ 000210319.pdf. Accessed 30 Nov 2020.

Publisher's Note Springer Nature remains neutral with regard to jurisdictional claims in published maps and institutional affiliations. 